\title{
Melittin: A Key Composition of Honey Bee Venom with Diverse Pharmaceutical Function
}

\author{
Sheng HUANG \\ Animal disease and Veterinary Research Institute \\ Chongqing Academy of Animal Science \\ Chongqing, China \\ e-mail: huangyun_ba@126.com \\ Xiaozhong WANG \\ Animal disease and Veterinary Research Institute \\ Chongqing Academy of Animal Science \\ Chongqing, China \\ e-mail: wxzcq@139.com
}

\author{
Jianhua WANG* \\ Bioengineering College \\ Chongqing University \\ Chongqing, China \\ e-mail: wjh@cqu.edu.cn
}

\author{
Chenghong LI \\ Animal disease and Veterinary Research Institute \\ Chongqing Academy of Animal Science \\ Chongqing, China \\ e-mail: lchenghong@126.com
}

\begin{abstract}
Melittin is the main toxic component in the the honey bee venom. It is a cationic, lytic peptide constituted by 26 amino acid residues. This peptide is an amphoteric molecule which the carboxy-terminal region is hydrophilic and the amino-terminal region is hydrophobic due to the presence of a series of positively charged amino acids. Melittin shows the interaction with biological membrane or enzyme to amphiphilic property. Based on these properties, melittin is an important candidate use for antibiotic-resistant bacteria, cancer and tumor and pathogenicity virus treatment. This review introduces the possible active mechanism of melittin and recent research progress in medical.
\end{abstract}

Keywords-melittin; active mechanism; anticancer; anti-viral; medical function

\section{INTRODUCTION}

Melittin is the main constituent in the honey bee venom which constitutes approximately $40-50 \%$ of the dry powder weight of the venom[1]. It is a small linear peptide with the chemical formula $\mathrm{C}_{131} \mathrm{H}_{228} \mathrm{~N}_{38} \mathrm{O}_{32}$ composed of 26 amimo acid residues[2]. Melittin has various biological, toxicological, pharmacodynamics and pharmacological properties, including strong interaction with cell lipid membranes, antifungal, antibacterial, antiviral and potential anti-tumor activities[3, 4]. Melittin is a potential pore forming peptide that can form four polymers and insert in the phospholipid bilayer, Therefore, it is able to study the interaction relationship between bioactive membrane and peptide by the biological activity[5-7]. Melittin was used to be a phospholipase A2 (PLA2) activator due to the discovery that it has an enhancing effect on PLA2 activity $[8,9]$. The interest of the medicinal properties of melittin increased greatly in the recent decades; therefore this paper brings an overview of recent pharmaceutical function researches of this peptide.

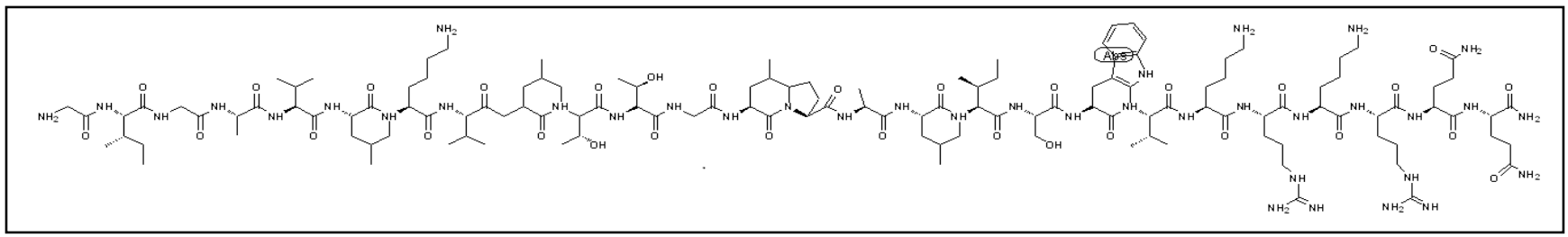

Figure 1. Structure of melittin

\section{PHySICOCHEMICAL PROPERTY AND ACTIVE MECHANISM OF MELITTIN}

\section{A. Physicochemical Property of Melittin}

Melittin is an amphiphilic polypeptide. The net charge of this peptide is 6+ at physiological $\mathrm{pH}$. One of the four positive charges is in the C-terminal region and the rest of two charges in the Lys-7 and the N-terminal group. The polar and non-polar amino acids asymmetric distribution lead melittin to be an amphipathic peptide when the peptide is develop to an $\alpha$-helical conformation[10]. Although, non-polar amino acids accounted for a large proportion in the structure of melittin, this peptide is marginally soluble in methanol but highly soluble in water. At low concentration, melittin is a monomer and forms a randomly coiled conformation in aqueous solution and self-assembly into tetramers in high-pH or ionic solution[11].

The melittin tetramer's three-dimensional structure in 
aqueous solution determined by $\mathrm{X}$-ray crystallographic analysis at $2 \AA$ resolution which the crystals grown in high ionic strength solution. In the tetramer crystal, each peptide chain is form of two $\alpha$-helical portions and the overall structure presents a curved shape. In another research[12], through NMR methods, with the change of temperature, melittin presents a conformational transition between the monomer and tetramer in aqueous solution and this change great relevance with proline residues isomers in melittin structure. In aqueous solution, the monomeric melittin self-assembly to a tetramer is increased with elevated ionic, melittin concentration, and high $\mathrm{pH}$. The fluorescence experiments shown that melittin for the most part was monomeric at very low ionic resolution[13]. On the contrary, high ionic strength and high concentration of the peptide promoted the aggregation at neutral $\mathrm{pH}$ solution.

\section{B. Membrane-Active Mechanism of Melittin}

Melittin generally used for membrane studies as it strong lipid membrane disrupt and lysis ability. This principle is an $\alpha$-helical structure melittin bind to lipid membrane in possible parallel or perpendicular way. In the perpendicular model, it is might be participate in pore formation by form a tetramer structure in lipid membrane [14, 15]. In 2010, Lee[16] found a new antimicrobial mechanism of melittin. The antifungal effect of melittin in C. albicans was detected by using fluorescence microscopy with FITC-annexin V, DAPI (4'-6-diamidino-2-phenyl -indole), and TUNEL (TdT-mediated dUTP Nick-End Labeling) staining. In addition, melittin increased the reactive oxygen species (ROS) production. The depth mechanism of melittin antimicrobial activity in C. albicans was further detected[17]. Experimental results revealed that melittin emerged highly reactive hydroxyl radicals $\left({ }^{\circ} \mathrm{OH}\right)$ that resulted in cell apoptosis.

\section{Biological Activity of Melittin}

\section{A. Anticancer Active of Melittin}

The possible anti-cancer, anti-tumor mechanism of melittin is: inhibited cell growth by disturbed cell growth cycle, then induces cell apoptosis and necrosis. In vitro experiment, it reveals a growth inhibition and lethality in human hepatoma and glioma cell[18]. In human hepatocellular carcinoma cell(HCC), a recombinant adenovirus that fusing an melittin gene (Ad-rAFP-Mel) used in the treatment of liver cancer [19]. The result showed that Ad-rAFP-Mel infection had an inhibitory effect on the proliferation of HCC cells.

Many research results showed that melittin can significantly inhibits the growth and induces cell apoptosis of tumor cells [20-23]. An article Recently published on melittin detailedly reviewed the main mechanism of melittin antitumor activity [24]. This review show that the interaction and treatment of melittin with several types of cancer, such as renal, lung, liver, prostate, bladder, breast. Melittin studied in vivo animal models have also demonstrated its tumor inhibitory and anti-proliferative activity[25]. However, some side effects like hemolysis and injury of liver and kidney were detected in the treatment process of melittin. To minimize these body damage effects, some modified strategies of melittin should be processed. A recombinant immunotoxin was obtained that an antigen binding to melittin[26]. This system was obtained by fusing genes which encoded a murine monoclonal antibody derivative with an oligonucleotide encoding melittin. This recombinant immunotoxin showed significantly binding and killing tumor cell properties in vitro. In Cao's study[27], a recombinant immunotoxin was obtained by fused melittin to an anti-asialoglycoprotein receptor (ASGPR) antibody (Ca). Moreover, the lysis efficacy and targeting ability of the fusion antibody were studied, results showed that the recombinant protein still kept the hemolytic activity of melittin but the lysis ability to HepG2 cells was improved. In order to reduce the lytic ability of melittin, a tumor matrix metalloproteinase2 (MMP2) cleavable melittin/avidin conjugated protein was built. It was inactive when melittin coupled to avidin, but once released from the conjugate content it induces immediate cell cytolytic [28].

In order to reduce the side effects, some researchers designed and synthesized a transporting vehicle of melittin. Through emulsion solvent diffusion method, nanoparticles were obtained by mixed melittin with the anionic detergent sodium dodecyl sulfate form into poly (D, L-lactide-co-glycolide acid) nanoparticles. Moreover, the in vitro studies showed that the growth inhibitory activity effects of melittin-loaded nanoparticles in breast cancer MCF-7 cells were significantly improved [29]. But this nanoparticles could not directly administrated as melittin could be released from the nanoparticles into blood vessels and induced lysis of red blood cells [30]. Further, a stable perfluorocarbon nanoparticles was designed to solve the disadvantages[31]. This kind of nanoparticles presented perfect pharmacokinetics, transported melittin to tumor cell and reduced tumor growth but no significant toxicity [32, 33].

\section{B. Antimicrobial Active of Melittin}

Melittin has showed powerfully antimicrobial activities but also has strong hemolytic and significant allergic properties[34, 35]. Merrifield worked on shortening the sequence, improving this antimicrobial peptide biological activity. Four cecropin A and melittin chimeric peptide derivatives were designed and synthesized, in vitro activity test showed good antibacterial activity against Gram-negative and Gram-positive bacteria but low cytotoxicity[36]. In addition, it is well known that methicillin-resistant Staphylococcus aureus (MRSA) was difficult to treat by existing antibiotics. A recent study showed[37] that MRSA-infected rats were treated by melittin, survived in MRSA-induced bacteraemia and restored from skin wounds. There result suggested that melittin could most likely be developed into new antibiotics or replacement. 


\section{Anti-Viral Active of Melittin}

Although disease caused by the virus is popular all over the world, but the effective drugs of treating viral infection is very shortage. The antiviral activities of melittin and its analogs were confirmed that they could inhibit the synthesis of viral protein particles like melittin-reduced the formation of HSV-1viral proteins [38]. In addition, melittin could inhibit replication of HIV-1 by suppressing viral gene expression[39]. Another study showed that a melittin loaded-immunoliposome was utilized to show the antiviral properties against fish viral haemorrhagic septicemia rhabdovirus (VHSV)[40]. Recently, a similar idea has been published that melittin could inhibit HIV-1 invasion by carried in a nanoparticle that might be used as a topical vaginal HIV-1 virucide[41].

\section{CONCLUSION}

Nowadays, the need for new effective antimicrobial, anticancer, antiviral drugs has become a priority and new strategies should be introduced to alternative current therapeutic regimen. Melittin is probably the most studied antimicrobial peptide with potential actions against bacteria, viruses and cancer cells, it has been extensively examined in vitro and in vivo experiment, although many bioactive mechanism remains to be illuminated.

Because of the strong hemolysis and the fast degradation by biological properties, there are many challenges should be over came in the way to develop melittin to novel and variety of actives drug, therefore reduce adverse effects and improve its bioavailability will become melittin follow-up research hot spot. Based on the above elaboration, we are looking for subsequent research. Firstly, melittin mainly extract from bee venom and a variety of structural analogues will generate during the period of melittin precursor convert into melittin[42]. Thus, to obtain high purity and yield of melittin will be the key and difficult point for future research. Some scholars expected to obtain high yield and purity of melittin by biological fermentation engineering technology, their work suggested that more engineered expression systems should be develop to reduce the cost of acquiring melittin[43-46]. Secondly, Chemical modification of structure of melittin or combined with other protein could enhance the biological stability. At the same time, the fusion protein of biological activity protein and melittin might generate synergy effect in organisms. So exploring different chemical modification or design and synthesis of different fusion protein will also become an important research direction in the future. Finally, although cytotoxic to the pathogenic microorganism, tumor and cancer cells, melittin is also toxic to normal tissues or organs. Therefore, without a suitable delivery system, its therapeutic potential cannot be achieved. This could be overcome by many kinds of melittin-loading nanoparticles that can safely transmit melittin to lesions by intravenous infusion, other like oral administration, mucosal drug delivery, controlled release and targeted nanoparticles should be develop to expand the range of applications of melittin and enhance its activity effect. With the development of above three areas, melittin will be the strongest potential to become the next generation of biological drugs.

\section{ACKNOWLEDGMENT}

This work was supported by Chongqing Academy of Animal Sciences applied basic research project (grant no.14451) and the Foundation and Advanced Research Project of CQ CSTC (2013jjB0011).

\section{REFERENCES}

[1] E, Habermann, “Bee and wasp venoms," Science, vol. 177, Jul. 1970, pp. 314-322, doi: 10.1126/science.177.4046.314.

[2] T. C. Terwilliger, L. Weissman, and D. Eisenberg, "The structure of melittin in the form I crystals and its implication for melittin's lytic and surface activities,” Biophysical Journal, vol. 37, Jan. 1982, pp. 353-361, 1982, doi:10.1016/S0006-3495(82)84683-3.

[3] J. Chen, and W. R. Lariviere, "The nociceptive and anti-nociceptive effects of bee venom injection and therapy: A double-edged sword," Progress in Neurobiology, vol. 92, Oct. 2010, pp. 151-183, doi:10.1016/j.pneurobio.2010.06.006.

[4] D. J. Son, J. W. Lee, Y. H. Lee, H. S. Song, C. K. Lee, and J. T. Hong, "Therapeutic application of anti-arthritis, pain-releasing, and anti-cancer effects of bee venom and its constituent compounds," Pharmacology \& Therapeutics, vol. 115, Aug. 2007, pp. 246-270, doi:10.1016/j.pharmthera.2007.04.004.

[5] G. Klocek, T. Schulthess, Y. Shai, and J. Seelig, "Thermodynamics of Melittin Binding to Lipid Bilayers. Aggregation and Pore Formation,” Biochemistry, vol. 48, Mar, 2009, pp. 2586-2596, doi:10.1021/bi802127h.

[6] L.Y. Chen, C.W. Cheng, J.J. Lin, and W.Y. Chen, "Exploring the effect of cholesterol in lipid bilayer membrane on the melittin penetration mechanism,” Analytical Biochemistry, vol. 367, Aug. 2007, pp. 49-55, doi:10.1016/j.ab.2007.04.039.

[7] B. Bechinger, "Structure and Functions of Channel-Forming Peptides: Magainins, Cecropins, Melittin and Alamethicin,” The Journal of Membrane Biology, vol. 156, Apr. 1997, pp. 197-211, doi:10.1007/s002329900201.

[8] S. V. Sharma, "Melittin-induced hyperactivation of phospholipase A2 activity and calcium influx in ras-transformed cells," Oncogene, vol. 8, Apr. 1993, pp. 939-947.

[9] T. Nishiya, "Interaction of melittin and phospholipase A2 with azobenzene-containing phospholipid,” J Biochem, vol. 109, no. 3, pp. 383-8, Mar, 1991.

[10] M. Dathe, and T. Wieprecht, "Structural features of helical antimicrobial peptides: their potential to modulate activity on model membranes and biological cells," Biochimica Et Biophysica Acta-Biomembranes, vol. 1462, Dec, 1999, pp. 71-87, doi:10.1016/S0005-2736(99)00201-1.

[11] C. E. Dempsey, “The actions of melittin on membranes,” Biochimica et Biophysica Acta (BBA) - Reviews on Biomembranes, vol. 1031, May. 1990, pp. 143-161, doi:10.1016/0304-4157(90)90006-X.

[12] Y. Miura, "NMR chemical shift analysis of the conformational transition between the monomer and tetramer of melittin in an aqueous solution," European Biophysics Journal with Biophysics Letters, vol. 45, May, 2016, pp. 347-354,doi:10.1007/s00249-015-1102-1.

[13] H. Raghuraman, and A. Chattopadhyay, "Effect of ionic strength on folding and aggregation of the hemolytic peptide melittin in solution," Biopolymers, vol. 83, Oct. 2006, pp. 111-121, doi:10.1007/s00249-015-1102-1.

[14] M. T. Lee, W. C. Hung, F. Y. Chen, and H. W. Huang, "Mechanism and kinetics of pore formation in membranes by water-soluble amphipathic peptides," Proceedings of the National Academy of Sciences of the United States of America, vol. 105, Apr. 2008, pp. 
5087-5092, doi: 10.1073/pnas.0710625105.

[15] K. Hristova, C. E. Dempsey, and S. H. White, "Structure, location, and lipid perturbations of melittin at the membrane interface," Biophysical Journal, vol. 80, Feb. 2001, pp. 801-811, doi:10.1016/S0006-3495(01)76059-6.

[16] C. Park, and D. G. Lee, "Melittin induces apoptotic features in Candida albicans," Biochemical and Biophysical Research Communications, vol. 394, Mar. 2010, pp. 170-172, doi:10.1016/j.bbrc.2010.02.138.

[17] J. Lee, and D. G. Lee, "Melittin triggers apoptosis in Candida albicans through the reactive oxygen species-mediated mitochondria/caspase-dependent pathway,” Fems Microbiology Letters, vol. 355, Jun. 2014, pp. 36-42, doi:10.1111/1574-6968.12450.

[18] H. Hu, D. Chen, Y. Li, and X. Zhang, "Effect of polypeptides in bee venom on growth inhibition and apoptosis induction of the human hepatoma cell line SMMC-7721 in-vitro and Balb/c nude mice in-vivo,” Journal of Pharmacy and Pharmacology, vol. 58, Jan. 2006, pp. 83-89, doi:10.1211/jpp.58.1.0010.

[19] B. Li, W. Gu, C. Zhang, X. Q. Huang, K. Q. Han, and C. Q. Ling, "Growth arrest and apoptosis of the human hepatocellular carcinoma cell line Bel-7402 induced by melittin,” Onkologie, vol. 29, Sept. 2006, pp. 367-371, doi:10.1159/000094711.

[20] S. H. Lee, Y. Y. Kang, H.-E. Jang, and H. Mok, "Current preclinical small interfering RNA (siRNA)-based conjugate systems for RNA therapeutics," Advanced Drug Delivery Reviews, vol. 104 Sept.2016, pp. 78-92, doi:10.1016/j.addr.2015.10.009.

[21] G. Qin, Y. Q. Chen, H. D. Li, S. Y. Xu, Y. M. Li, J. Sun, W. Rao, C. W. Chen, M. D. Du, K. Y. He, and Y. Ye, "Melittin inhibits tumor angiogenesis modulated by endothelial progenitor cells associated with the SDF-1 alpha/CXCR4 signaling pathway in a UMR-106 osteosarcoma xenograft mouse model,” Molecular Medicine Reports, vol. 14, Jul, 2016, pp. 57-68, doi:10.3892/mmr.2016.5215.

[22] G. M. Kong, W. H. Tao, Y. L. Diao, P. H. Fang, J. J. Wang, P. Bo, and F. Qian, "Melittin induces human gastric cancer cell apoptosis via activation of mitochondrial pathway," World Journal of Gastroenterology, vol. 22, Mar. 2016, pp. 3186-3195, doi:10.3748/wjg.v22.i11.3186.

[23] X. Q. Wu, B. Zhao, Y. H. Cheng, Y. Yang, C. Huang, X. M. Meng, B. M. Wu, L. Zhang, X. W. Lv, and J. Li, "Melittin induces PTCH1 expression by down-regulating $\mathrm{MeCP} 2$ in human hepatocellular carcinoma SMMC-7721 cells," Toxicology and Applied Pharmacology, vol. 288, Oct. 2015, pp. 74-83, doi:10.1016/j.taap.2015.07.010.

[24] G. Gajski, and V. Garaj-Vrhovac, "Melittin: A lytic peptide with anticancer properties," Environmental Toxicology and Pharmacology, vol. 36, Sep. 2013, pp. 697-705, doi:10.1016/j.etap.2013.06.009.

[25] S. J. Liu, M. Yu, Y. He, L. Xiao, F. Wang, C. C. Song, S. H. Sun, C. Q. Ling, and Z. H. Xu, "Melittin prevents liver cancer cell metastasis through inhibition of the Rac1-dependent pathway," Hepatology, vol. 47, Jun. 2008, pp. 1964-1973, doi:10.1002/hep.22240.

[26] R. D. Dunn, K. M. Weston, T. J. Longhurst, G. G. Lilley, D. E. Rivett, P. J. Hudson, and R. L. Raison, "Antigen binding and cytotoxic properties of a recombinant immunotoxin incorporating the lytic peptide, melittin,” Immunotechnology, vol. 2, Sept. 1996, pp. 229-240, doi:10.1016/S1380-2933(96)00055-3.

[27] X. R. Zhao, Z. Yu, W. T. Dai, Z. J. Yao, W. Zhou, W. P. Zhou, J. L. Zhou, Y. G. Yang, Y. C. Zhu, S. D. Chen, and L. M. Cao, "Construction and characterization of an anti-asialoglycoprotein receptor single-chain variable-fragment-targeted melittin," Biotechnology and Applied Biochemistry, vol. 58, Nov. 2011, pp. 405-411, doi: 10.1002/bab.57.

[28] L. Holle, W. Song, E. Holle, Y. Z. Wei, T. Wagner, and X. Z. Yu, “A matrix metalloproteinase 2 cleavable melittin/avidin conjugate specifically targets tumor cells in vitro and in vivo," International Journal of Oncology, vol. 22, Jan. 2003, pp. 93-98, doi:10.3892/ijo.22.1.93.
[29] L. Yang, F. Cui, K. Shi, D. M. Cun, and R. Wang, "Design of high payload PLGA nanoparticles containing melittin/sodium dodecyl sulfate complex by the hydrophobic ion-pairing technique,” Drug Development and Industrial Pharmacy, vol. 35, May. 2009, pp. 959-968, doi:10.1080/03639040902718039.

[30] J. F. Popplewell, M. J. Swann, N. J. Freeman, C. McDonnell, and R. C. Ford, "Quantifying the effects of melittin on liposomes," Biochimica Et Biophysica Acta-Biomembranes, vol. 1768, Jan. 2007, pp. 13-20, doi:10.1016/j.bbamem.2006.05.016.

[31] N. R. Soman, G. M. Lanza, J. M. Heuser, P. H. Schlesinger, and S. A. Wickline, "Synthesis and characterization of stable fluorocarbon nanostructures as drug delivery vehicles for cytolytic peptides," Nano Letters, vol. 8, Apr. 2008, pp. 1131-1136, doi:10.1021/nl073290r.

[32] H. Pan, N. R. Soman, P. H. Schlesinger, G. M. Lanza, and S. A. Wickline, "Cytolytic peptide nanoparticles ('NanoBees') for cancer therapy,” Wiley Interdisciplinary Reviews-Nanomedicine and Nanobiotechnology, vol. 3, Jun, 2011, pp. 318-327, doi:10.1002/wnan.126.

[33] N. R. Soman, S. L. Baldwin, G. Hu, J. N. Marsh, G. M. Lanza, J. E. Heuser, J. M. Arbeit, S. A. Wickline, and P. H. Schlesinger, "Molecularly targeted nanocarriers deliver the cytolytic peptide melittin specifically to tumor cells in mice, reducing tumor growth," Journal of Clinical Investigation, vol. 119, Sep. 2009, pp. 2830-2842, doi:10.1172/JCI38842.

[34] S. K. Zhang, Q. Ma, S. B. Li, H. W. Gao, Y. X. Tan, F. Gong, and S. P. Ji, "RV-23, a Melittin-Related Peptide with Cell-Selective Antibacterial Activity and High Hemocompatibility,” Journal of Microbiology and Biotechnology, vol. 26, Jun. 2016, pp. 1046-1056, doi: 10.4014/jmb.1510.10074.

[35] X. Wu, A. K. Singh, X. Y. Wu, Y. Lyu, A. K. Bhunia, and G. Narsimhan, "Characterization of antimicrobial activity against Listeria and cytotoxicity of native melittin and its mutant variants," Colloids and Surfaces B-Biointerfaces, vol. 143, Jul, 2016, pp 194-205, doi:10.1016/j.colsurfb.2016.03.037.

[36] H. G. Boman, D. Wade, I. A. Boman, B. Wåhlin, and R. B. Merrifield, "Antibacterial and antimalarial properties of peptides that are cecropin-melittin hybrids,” FEBS Letters, vol. 259, Dec. 1989, pp. 103-106,doi:10.1016/0014-5793(89)81505-4.

[37] J. H. Choi, A. Y. Jang, S. Lin, S. Lim, D. Kim, K. Park, S. M. Han, J. H. Yeo, and H. S. Seo, "Melittin, a honeybee venom-derived antimicrobial peptide, may target methicillin-resistant Staphylococcus aureus,” Molecular Medicine Reports, vol. 12, Nov. 2015, pp. 6483-6490, doi: 10.3892/mmr.2015.4275.

[38] A. Baghian, J. Jaynes, F. Enright, and K. G. Kousoulas, "An amphipathic alpha-helical synthetic peptide analogue of melittin inhibits herpes simplex virus-1 (HSV-1)-induced cell fusion and virus spread,” Peptides, vol. 18, Oct. 1996, pp. 177-183, doi:10.1016/S0196-9781(96)00290-2.

[39] M. Wachinger, A. Kleinschmidt, D. Winder, N. von Pechmann, A. Ludvigsen, M. Neumann, R. Holle, B. Salmons, V. Erfle, and R. Brack-Werner, "Antimicrobial peptides melittin and cecropin inhibit replication of human immunodeficiency virus 1 by suppressing viral gene expression,” Journal of General Virology, vol. 79, Apr. 1998 pp. 731-740, doi:10.1099/0022-1317-79-4-731.

[40] A. Falco, E. Barrajon-Catalan, M. P. Menendez-Gutierrez, J. Coll, V. Micol, and A. Estepa, "Melittin-loaded immunoliposomes against viral surface proteins, a new approach to antiviral therapy," Antiviral Research, vol. 97, Feb. 2013, pp. 218-221, doi:10.1016/j.antiviral.2012.12.004.

[41] J. L. Hood, A. P. Jallouk, N. Campbell, L. Ratner, and S. A. Wickline, "Cytolytic nanoparticles attenuate HIV-1 infectivity," Antiviral Therapy, vol. 18, Sept. 2012, pp. 95-103, doi: 10.3851/IMP2346.

[42] N. Peiren, D. C. de Graaf, F. Vanrobaeys, E. L. Danneels, B. Devreese, J. Van Beeumen, and F. J. Jacobs, "Proteomic analysis of the honey bee worker venom gland focusing on the mechanisms of protection against tissue damage,” Toxicon, vol. 52, July. 2008, pp. 72-83, http://dx.doi.org/10.1016/j.toxicon.2008.05.003.

[43] R. J. Wu, Q. Wang, Z. J. Zheng, L. M. Zhao, Y. J. Shang, X. B. Wei, 
X. D. Liao, and R. J. Zhang, "Design, characterization and expression of a novel hybrid peptides melittin (1-13)-LL37 (17-30)," Molecular Biology Reports, vol. 41, July. 2014, pp. 4163-4169, doi:10.1007/s11033-013-2900-0.

[44] C. Husseneder, J. R. Donaldson, and L. D. Foil, "Genetically Engineered Yeast Expressing a Lytic Peptide from Bee Venom (Melittin) Kills Symbiotic Protozoa in the Gut of Formosan Subterranean Termites,” Plos One, vol. 11, Mar, 2016, pp. 9, doi:10.1371/journal.pone.0151675.

[45] K. Qian, L. Y. Sun, G. Q. Zhou, H. X. Ge, L. Xiao, Y. Yang, L. Z.
Wen, and Z. L. Shen, "Design of Melittin-Thanatin Hybrid Peptide and Expression in Fission Yeast," 2014 2nd International Conference in Humanities, Social Sciences and Global Business Management, Lecture Notes in Management Science, Lecture Notes in Management Science, Jun. 2014, pp. 20-27,

[46] Y. Cao, R. Q. Yu, Y. Liu, H. X. Zhou, L. L. Song, Y. Cao, and D. R. Qiao, "Design, Recombinant Expression, and Antibacterial Activity of the Cecropins-Melittin Hybrid Antimicrobial Peptides," Current Microbiology, vol. 61, Sept, 2010, 169-175, doi: 10.1007/s00284-010-9592-7. 